\title{
A Multi-Energetic Modeling Approach based on Bond Graph Applied to In-Wheel-Motor Drive System
}

\author{
Sihem Dridi ${ }^{1}$, Ines Ben Salem ${ }^{2}$, Lilia El Amraoui ${ }^{3}$ \\ UR: SMS, ENICarthage, \\ 2035 Tunis-Carthage, Tunisie
}

\begin{abstract}
This paper proposes a multi-energetic modeling approach based on Bond Graph tool to modeling a mechatronic system. The use of this approach allows to better understand the real behavior of such system as well as to express the interaction between the elements and their environments. Firstly, the dynamic model of the In-Motor-Wheel Drive System is built using the Bond Graph tool, which is well suited for a multienergetic modeling system, where several types of energies are included. Secondly, the control system is established and is based on the Pulse Width Modulation (PWM) technique. Finally, the dynamic model is coupled to the control system. They are then successfully implemented and simulated under 20-Sim environment. The simulation results present the performance and the efficiency of the adapted tool not only for dynamic modeling of the synergetic systems, but also to elaborate its control system.
\end{abstract}

Keywords-Multi-energetic approach; bond graph tool; PWM; 20-Sim environment; in-wheel motor drive system; mechatronic system

\section{INTRODUCTION}

The mechatronic system is the synergistic and systemic combination of various components [1] such as actuators, sensors, input/output signal conditioning and interfacing unit, digital control architecture and displays. These components belong to various energy domains such as electronic, mechanic, pneumatic, hydraulic, automatic and computing [2]. 1.

The signal flows among these components is shown in Fig.

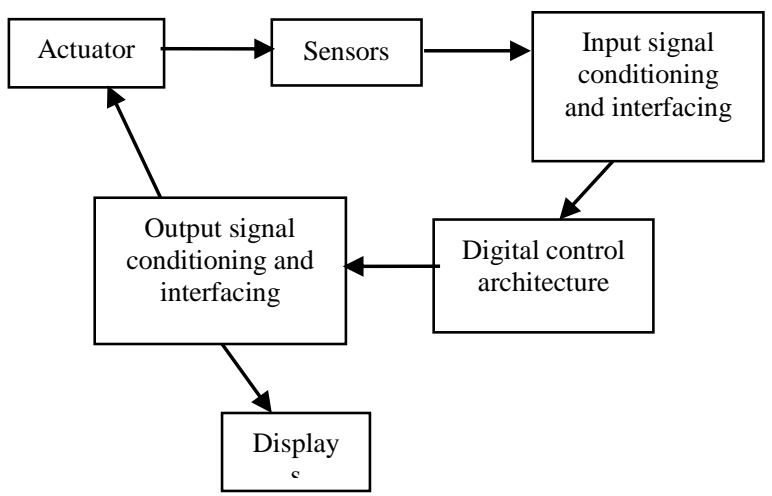

Fig. 1. Various Components of a Mechatronic System [1].
Currently, mechatronics is used in many industrial fields such as the automotive field, due to the development of more powerful, economical, reliable and versatile (flexible) systems and to meet the requirements requested by the user.

The In-Two-Wheels Motors System Drive of an Electric Vehicle is one of the mechatronic application developed in the automotive field. Its advantage includes high efficiency, good repartition of drive power, high performance, safety, stability of the vehicle and optimal size of the system. But, this system has a complicated assembly. This complexity is linked to the [3]:

- multiplicity of subsystems into strong interactions with each other and with its environments;

- superposition of different physical behaviors such as mechanics, electrics, hydraulics and aerodynamics;

- multi-functionality of the system;

- nonlinearity of the dynamic behavior of the elements;

Consequently, the dynamic modeling and development of the control system of such a system have become difficult tasks. This involves the use of an appropriate modeling approach in order to better understand the real behaviors of this system [4].

In this context, this paper aims to a development of a multienergy approach based on the Bond Graph tool (BG). The need for such an approach consists of a need to bring a methodological aspect to answer the difficulties of modeling, analysis and structuring of the control. The benefit of this approach consists to represent interdisciplinary system systematically.

The particularity of the proposed approach is the determination of the energetic model of a system from its physical representation using a unified energy description language [5], regardless of physics domain and taking into account the interaction of their elements with each other and with the environment in where they operate. Unlike the analytical modeling approach is based mathematical functions. As well as it treats elements of the system in an isolated way by field of discipline.

In addition, this approach gives a structural readability of the system and a visibility on the transfer of energy between 
the elements [6]. These reasons facilitate the development of the control system based on the BG model.

In this article, the BG-based energy modeling approach is applied to the modeling of the In-Wheel-Motor drive system and to the development of its control system which is based on the sinusoidal PWM technique to control the vehicle speed.

The 20-Sim software is selected to implement and simulate the BG dynamic model system.

This paper is composed of five parts. Firstly, a multienergetic modeling approach based on Bond Graph tool is presented. Secondly, a brief description of the studied system is presented. Thirdly, the BG model is built. Fourthly, a closed control loop related to vehicle speed is elaborated and it is applied to the dynamic modeling system. Finally, simulation results are presented and discussed.

\section{Multi-EnERGETIC MODELING APPROACH BASED ON BG}

In this section, a multi-energetic modeling approach based on BG tool is presented.

\section{A. Concept of a Multi-Energetic Modeling Approach}

A multi-energetic modeling approach based on the BG tool rests a unified graphical language and systemic method to model and analyze dynamic systems. The BG tool is based on energy transfer modeling contained in the physical systems. This exchange of energy is represented in graphical form [7].

\section{B. Steps of a Multi-Energetic Modeling Approach}

The BG presents the modeling process step by step in a hierarchical and structural way. The different steps of the tool BG are shown in Fig. 2.

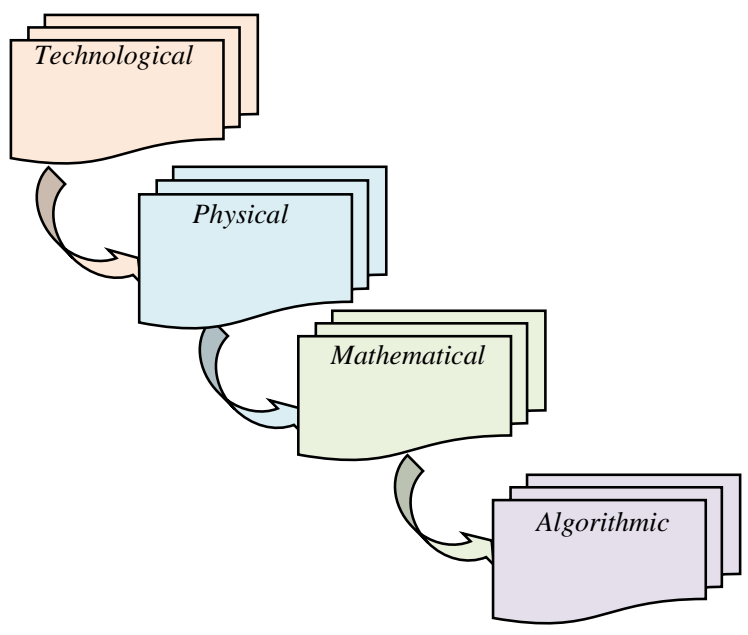

Fig. 2. Various Steps of BG.

BG methodology is composed of four levels [8], [9]:

1) The technological level: consists of a functional analysis of the system called "Word BG". It decomposes the system into interconnected subsystems. The inputs and the outputs of each subsystem are power variables ("effort" and "flow").

2) The physical level: consists of a phenomenological analysis. The various physical phenomena of each subsystem (dissipation of energy, transformation, accumulation, sources) are represented by the basic elements of Bond Graph which are presented by Fig.3.

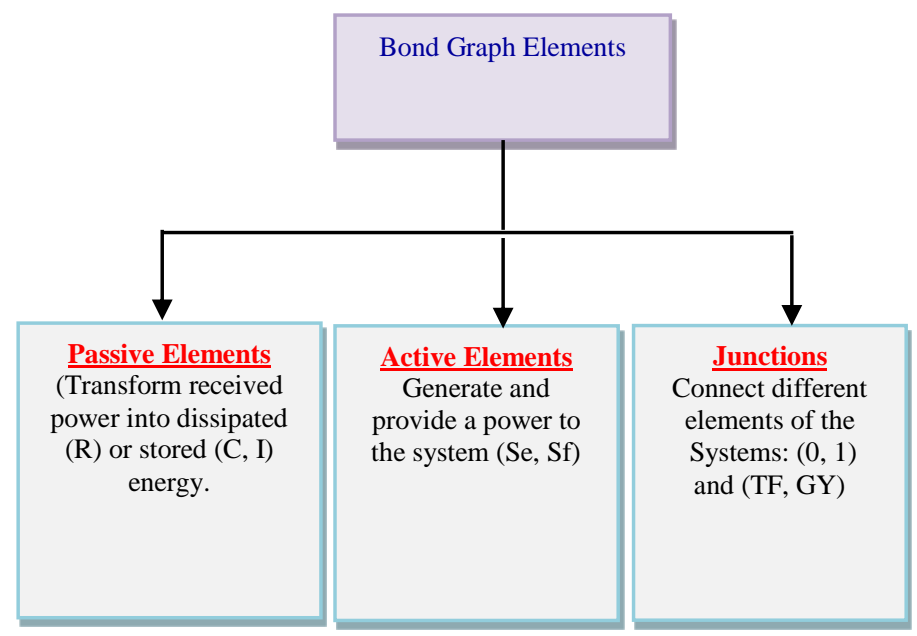

Fig. 3. Basic Elements of Bond Graph [10], [11].

3) The mathematical level: the dynamic equation (algebraic or differential) is deducted directly from the graphical model using the causality notion. From the transfer functions the control system is elaborated.

4) The algorithmic level: consists of the simulation of the diffusion parameters found.

\section{STUDIED SYSTEM}

\section{A. Physical Description}

The Electric vehicle equipped with In-Wheel Motors System is proposed. In this paper, only the rear drive system is considered. This system is composed of three parts.

The first part is vehicle dynamic which presents the mechanical aspect of the vehicle. This part is equipped with a chassis, wheels, suspension systems and environment forces.

Second part is the traction which provides the traction force. This force assures movement of the vehicle. This force assures movement of the vehicle. It is equipped with a threephase inverter, a common battery and an electric actuator such as a PM Synchronous Motor (PMSM) that is widely used in automotive applications especially with in wheel motors. Its advantages include high torque, large power to weight ratio and high efficiency and robustness compared with DC motor and IM [12].

Third is the central part. It generates the information and the control law.

Fig. 4 shows a simplified diagram of the rear traction system of the electric vehicle. It shows the various elements making up the system. 


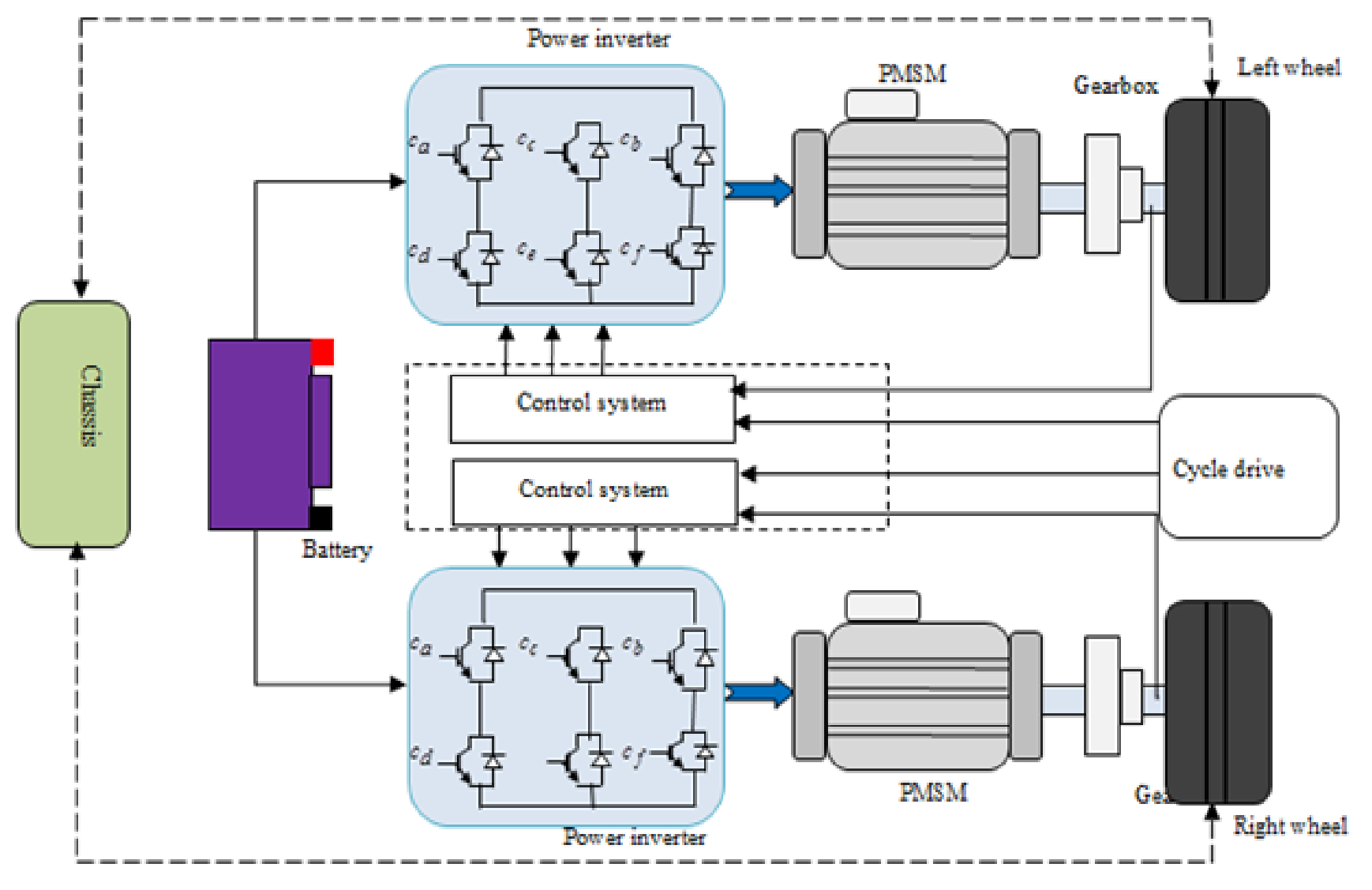

Fig. 4. Schematic Diagram of the Studied System.

\section{B. Dynamic Equation}

The equations corresponding to the various subsystems ranging from the battery to the chassis are defined in this section.

1) Dynamic modeling of the PMSM: It is presented as a coupling of electrical, magnetic and mechanical subsystems. The dynamic equations of PMSM are described in the rotating $(\mathrm{d}-\mathrm{q})$ reference frame as follows [13]:

$$
\begin{aligned}
& \left\{\begin{array}{l}
V_{d}=R_{s} i_{d}+L_{d} \frac{d i_{d}}{d t}-p \Omega_{m} L_{q} i_{q} \\
V_{q}=R_{s} i_{q}+L_{q} \frac{d i_{q}}{d t}+p \Omega_{m}\left(L_{d} i_{d}+\psi_{f}\right)
\end{array}\right. \\
& \Gamma_{e m}=p\left[\psi_{f}+\left(L_{d}-L_{q}\right) i_{d}\right] i_{q} \\
& J_{m} \frac{d \Omega_{m}}{d t}=\Gamma_{m}-\Gamma_{w}-B_{m} \Omega_{m} \\
& \Omega_{w_{i}}=k_{\text {red }} \Omega_{m_{i}}
\end{aligned}
$$
by:

The second conversion concerns the wheel and is written

$$
\Gamma_{w_{i}}=R_{w} F_{w_{i}}
$$

$\Omega_{w_{i}}=\frac{V_{v e h}}{R_{w}}$

2) Dynamic Modeling of the Chassis: This dynamic is given by equation (7) which presents the relation between the acceleration of the vehicle and traction force [5]:

$M \frac{d V_{v e h}}{d t}=F_{\text {tot }}-F_{\text {res }}$

$F_{t o t}$ is the tractive force generated by the PMSM.

$F_{r e s}$ is the resistance force presents the environment force and is expressed as:

$$
F_{\text {res }}=F_{\text {roll }}+F_{\text {areo }}+F_{\text {slope }}
$$

The expression of each force is given respectively by the equations below:

$$
\begin{aligned}
& F_{\text {areo }}=\frac{1}{2} \rho C_{d} A_{F} V_{\text {veh }}^{2} \\
& F_{\text {slope }}=M g \sin (\alpha)
\end{aligned}
$$


$F_{\text {roll }}=f_{r} M g$

\section{APPLICATION MULTI-ENERGETIC APPROACH MODELING BASED ON BG}

This section presents the dynamic modeling of the studied system, including the word BG associated with the system and the BG model of the global system.

\section{A. Word $B G$}

From the description of the studied system presented above, a functional analysis is performed the word BG is obtained and is illustrated by Fig.5.

The nomenclature Table presents the different symbols and variables.
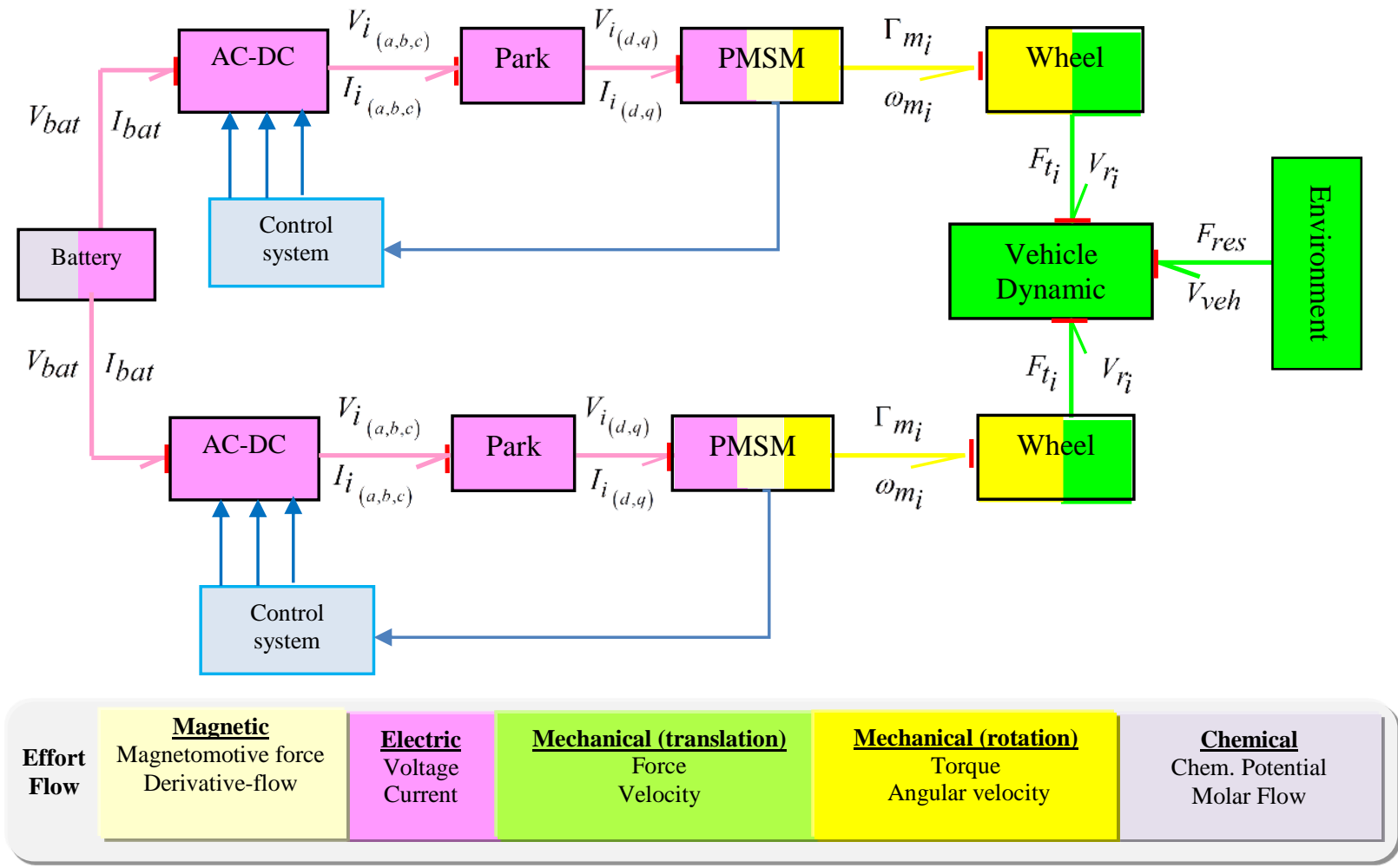

Fig. 5. Word BG of the Studied System.

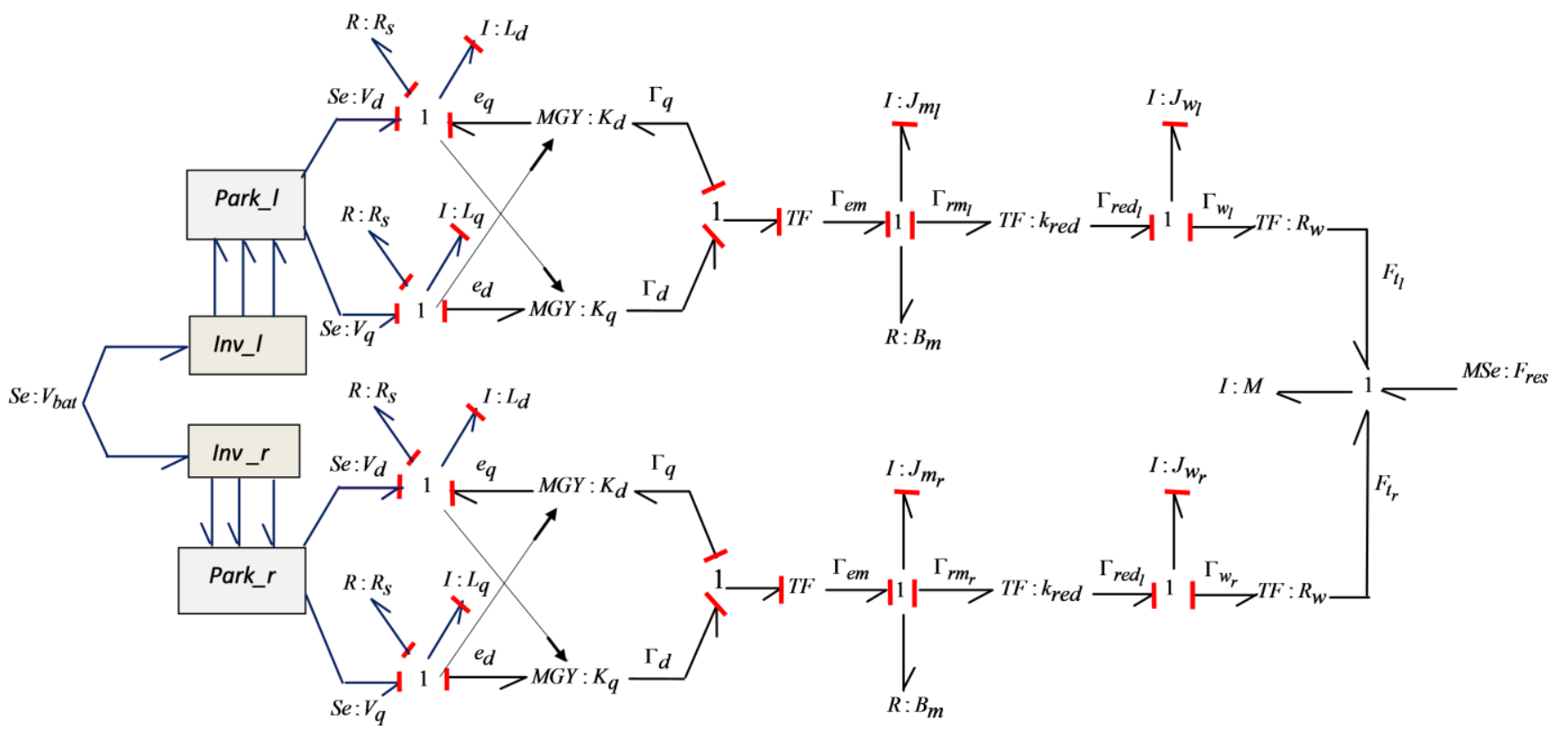

Fig. 6. BG Model of the Studied System. 
In the Word BG, the subsystems are composed with technological components which are designated by Words. The inputs and outputs are the energetic interactions that are represented by the power variables. There are two types of power sources: the engine and the environment. The motor provides a torque then it applies to the wheel via a speed reducer. When the vehicle is in motion, the environment generates forces that are applied to the wheel and the vehicle chassis. The Word BG allows a macroscopic representation of the system under consideration.

The next step is to detail each block of the BG to word to in order to obtain the detailed BG of the proposed system.

\section{B. BG Model Construction}

The BG model of the studied system is described by Fig.6. This model presents the phenomenological analysis of the studied system. The construction of the complete BG model is deduced directly from the physical modeling system and the Word BG.

In this study, the PMSM is powered by the DC voltage produced by the battery via the Voltage Source Inverter (VSI). In the BG model, the battery is modeled by the effort source (Se).

The VSI is represented by three transformers modulated ( $M T F$ ) and have the gains $\eta_{1}, \eta_{2}$ et $\eta_{3}$.

In Fig. 6, the electrical model of PMSM is represented by I and $\mathrm{R}$, that are present respectively the inductance and resistor of the PMSM.

I: $J_{m i}$ and $R: B_{m i}$ are respectively represented inertia and coefficient of friction of the mechanical model of the PMSM.
MGY: $k_{\mathrm{i}}$ represents the energy transfer between the two sub-models: electrical and mechanical, whose represents the electromotive force.

The dynamic model of the PMSM is composed with an electrical, a magnetic and a mechanical model.

The effort provided by PMSM is transmitted to wheel through the gearbox. That is represented by the transformer element (TF) and has a constant gain. The wheel transforms the torque to a force. This transformation is represented by a transformer element (TF) and it has a constant gain.

The dynamic model of the vehicle is modeled by an energy element (I).

The environment forces are represented by modulated effort sources (MSe).

The advantage BG model is that can be used to resolve many problems such as control, diagnosis, Fault Tolerant Control, etc.

\section{DEVElOPMENT OF THE CONTROL LAWS}

In our application, the desired output to be controlled is the speed of the vehicle.

The design of the control laws of this system is based on a mathematical model (state representation) obtained from the BG model using the mathematical step of Bond Graph tool.

Obtaining the mathematical equations is by applying the basic rules of the BG to the various junctions of the model. These rules are implemented by the constitutive laws of the BG elements concerned.

The control system coupled to the physical vehicle model is presented in Fig. 7.

Process: Vehicle system

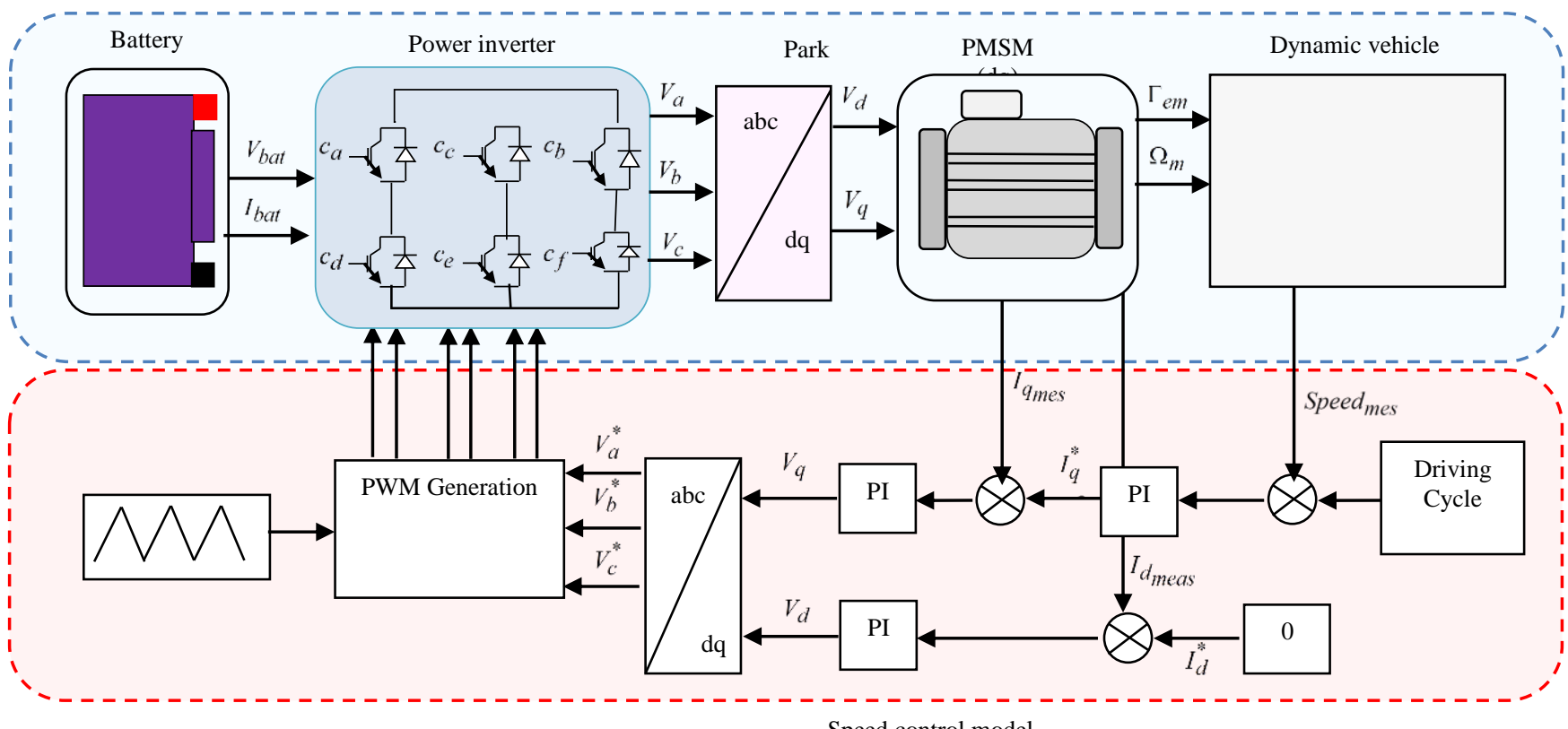

Speed control model

Fig. 7. Control System. 
The closed loop control includes two control loops. The inner loop regulates the motor stator currents using two PI current controllers in Park reference frame and compensations of EMFs.

The role of this loop is to obtain the voltage reference in the (d-q) frame.

The equation (13) presents the current control strategy:

$$
\begin{aligned}
& V_{d_{\text {ref }}}=\left[K_{p}+\frac{K_{I}}{p}\right]\left(I_{d_{\text {ref }}}-I_{d_{\text {meas }}}\right)+e_{d_{\text {meas }}} \\
& V_{q_{\text {ref }}}=\left[K_{p}+\frac{K_{I}}{p}\right]\left(I_{q_{\text {ref }}}-I_{q_{\text {meas }}}\right)+e_{q_{\text {meas }}}
\end{aligned}
$$

The outer loop controls the motor's speed. It's used PI controller to provide the total force reference for the velocity measurement and reference using a compensation of the resistive force (if it can be measured or estimated). It is expressed by following equation:

$$
F_{\text {tot }_{\text {ref }}}=\left[K_{p}+\frac{K_{I}}{p}\right]\left(V_{\text {veh }_{\text {ref }}}-V_{\text {veh }_{\text {meas }}}\right)+F_{\text {res }_{\text {meas }}}
$$

\section{A. Sinusoidal PWM control Strategy}

The PWM model generates the control signals of the inverter. The basic concept of the PWM technique is the comparison of a triangular wave with the fundamental sinusoidal modulation wave as presented in Fig. 8.

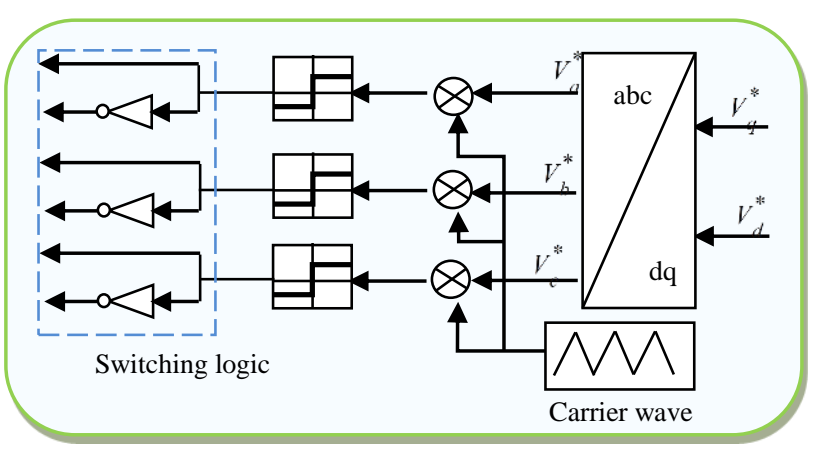

Fig. 8. PWM Model.

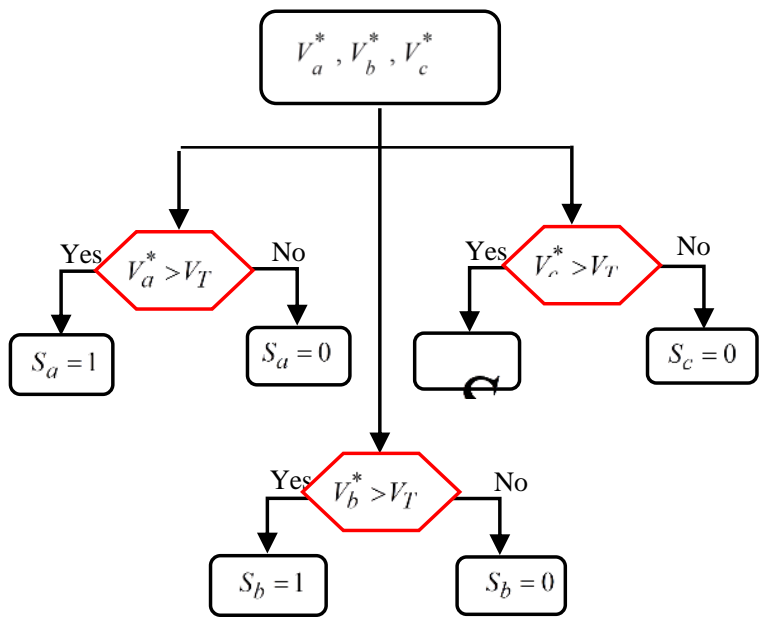

Fig. 9. Algorithm of the PWM Model.
The outputs of PWM go through Controlled Voltage Source blocks before being applied to the PMSM stator windings.

The algorithm of PWM is shown in Fig. 9

\section{SimUlation RESUlTS AND ANALYSIS}

\section{A. Simulation Results}

In this section, the BG model and its control system are implemented and simulated under 20-Sim software environment [14]. 20-sim is a valuable simulation tool used to model, investigate and simulation of the dynamic behavior of mechatronic system. It is dedicated to the bond graph application. The choice of 20-Sim is justified by the following advantages [15]:

- Ability to simulate and analyze the behavior of multidomain dynamic systems and create its control systems;

- Ability to present a model graphically, similar to drawing an engineering scheme;

- Ability to even generate $\mathrm{C}$-code and run this code on hardware for rapid prototyping and HIL-simulation;

- Creation of models very quickly and intuitively;

- Ability to create models using equations, block diagrams, physical components and bond graphs.

In order to characterize the system behavior and the performances of the proposed approach, simulations were carried using the model of Fig. 7. The specifications of the PMSM are shown in Table I and in Table II, the specifications of the dynamic vehicle.

The simulations are carried out in three cases:

1) Case A: Flat road with constant speed.

2) Case B: Flat road with $10 \%$ slope and constant speed.

3) Case C: Flat road with variable speed.

1) Case A: Flat road with constant speed $80 \mathrm{~km} \mathrm{~V}$ : In this case, we applied a constant speed reference at $80 \mathrm{~km} \backslash \mathrm{h}$ with the flat road condition. Fig.10 shows the vehicle's speed characteristics. At constant reference speed, the vehicle achieves a speed of $80 \mathrm{~km} \backslash \mathrm{h}$. once the speed reaches a steady value with a small overshoot due to environment force variations.

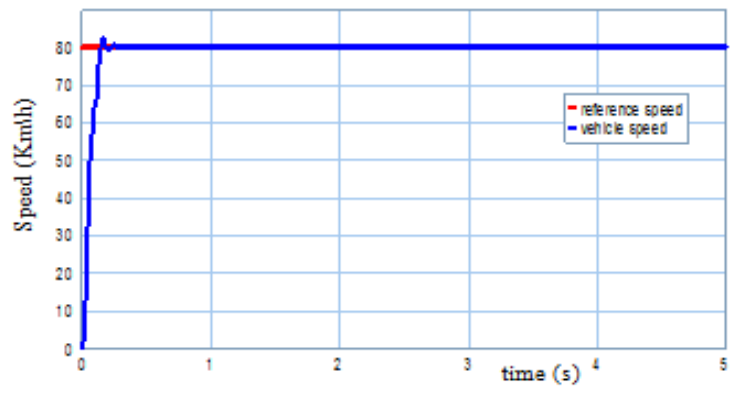

Fig. 10. Vehicle Speed Characteristics for Case A. 
2) Case B: Flat road with 10\% slope at constant speed: In this case, we applied a constant speed at $80 \mathrm{Km} \backslash \mathrm{h}$ with the road inclined with slope $10 \%$ at $2.5 \mathrm{~s}$. The speed stays always the same and the road slope does not affect the control of the vehicle speed, as shown in Fig. 11.

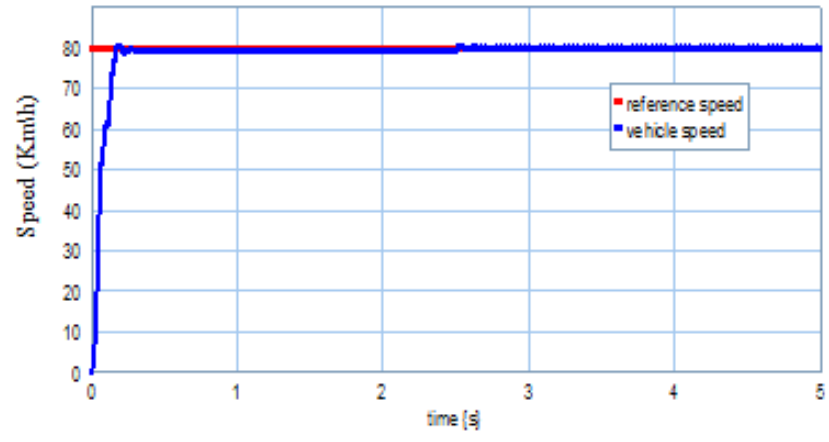

Fig. 11. Vehicle Speed Characteristics for Case B.

3) Case C: Flat road with variable speed: In this case, we applied a variable speed reference between $20 \mathrm{~km} / \mathrm{h}$ and $55 \mathrm{~km} \backslash \mathrm{h}$, with flat road condition. Fig. 12 shows the speed characteristics of the vehicle with various ranges of speed. We conclude that the speed reference is variable and the motor reaches the desired values very quickly with PI control.

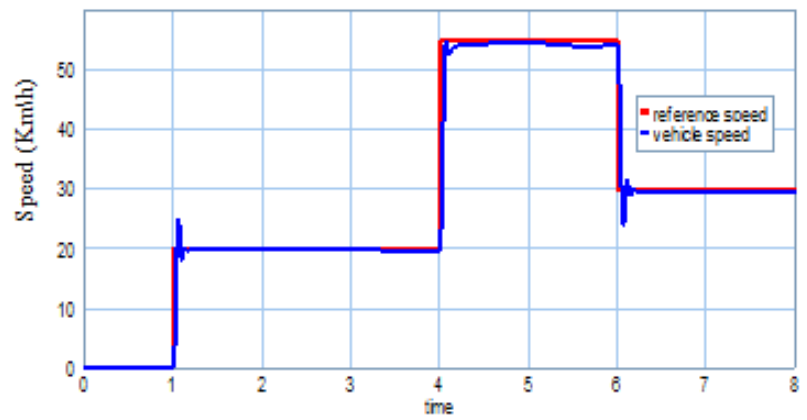

Fig. 12. Vehicle Speed Characteristics for Case C.

\section{B. Analysis of Simulation Results}

The simulation results show efficiency and high performances of an energetic modeling approach based on Bond Graph tool for modeling and elaborate a control system for complex and synergistic system. As well as shows, the potential of bond graph to couple two different graphical descriptions: structural (BG) and functional (informational graph) the same model and simulate together under 20-Sim software. The simulation of the speed control system obtained from the BG model for different speed variations and states of the road shows the effectiveness of the simulated control system.

\section{VII.CONCLUSION}

In this paper, a multi-energy and multi-physical modeling approach based on a bond graph tool is applied to model and to control a mechatronic system with multi-energy character. Firstly, In-Wheel Motor System Drive model is built. Secondly, its control system is elaborated. Finally, the BG model and control system are implemented under 20-Sim software.

The Bond Graph model of the proposed system is obtained and its control system is validated by simulations.

The study and the simulations show that an energy modeling approach based on BG tool has once again demonstrated its great potential, not only for constructing compact models where different fields of physics and energy but also to elaborate the control system from BG model.

In future work, the BG will be applied for analysis of controllability and observability, diagnosis, supervision of the studied system.

TABLE I. SPECIFICATIONS OF THE PMSM

\begin{tabular}{|l|l|l|}
\hline Symbol & Description & Value \\
\hline$J_{m}$ & Wheel inertia & $0.8 \mathrm{e}^{-3} \mathrm{Kg} / \mathrm{m}^{2}$ \\
\hline$V_{\text {bat }}$ & Battery voltage & $400 \mathrm{~V}$ \\
\hline$L_{d}, L_{q}$ & $d, q$ axis inductance & $0.2 \mathrm{mH}$ \\
\hline$R_{S}$ & stator resistance & $0.34 \mathrm{Ohm}$ \\
\hline$\Psi_{d}, \Psi_{q}$ & $d, q$ axis flux & $0.08 \mathrm{~Wb}$ \\
\hline $\mathrm{P}$ & Pole pairs & 4 \\
\hline
\end{tabular}

TABLE II. SPECIFICATIONS OF DYNAMIC VEHICLE

\begin{tabular}{|l|l|l|}
\hline Symbol & Description & Value \\
\hline$C_{d}$ & aerodynamic coefficient & 0.55 \\
\hline$\rho$ & Air density & 1.25 \\
\hline$A_{F}$ & Front area of vehicle & $1.8 \mathrm{~m}^{2}$ \\
\hline$M$ & chassis mass & $800 \mathrm{Kg}$ \\
\hline$R_{w}$ & Wheel Radius & $0.296 \mathrm{~m}$ \\
\hline
\end{tabular}


NOMENCLATURES

\begin{tabular}{|l|l|}
\hline Symbol & Description \\
\hline$J_{w}$ & Wheel inertia (motor included) \\
\hline $\mathrm{M}$ & vehicle mass \\
\hline$\lambda$ & Slip ratio \\
\hline$\mu$ & Friction coefficient \\
\hline$\Gamma_{w}$ & Wheel torque \\
\hline$\alpha$ & Angle of the slope \\
\hline$f_{r}$ & Friction coefficient \\
\hline $\mathrm{g}$ & Acceleration of gravity \\
\hline$\rho$ & Air density \\
\hline$C_{d}$ & Aerodynamic coefficient \\
\hline$V_{v e h}$ & Linear speed of vehicle \\
\hline$A_{F}$ & front area of vehicle \\
\hline$i_{d}, i_{q}$ & d and $q$ axis current \\
\hline$R_{w}$ & Wheel raduis \\
\hline$\Gamma_{m}$ & Motor torque \\
\hline$\Omega_{m}$ & Angular speed \\
\hline$V_{d}, V_{q}$ & $d$ and $q$ axis voltage \\
\hline$R_{s}$ & stator resistance \\
\hline$L_{d}, L_{q}$ & $d$ and $q$ axis inductance \\
\hline$\psi_{f}$ & Permanent magnet flux \\
\hline$\psi_{d}, \psi_{q}$ & $\mathrm{~d}$ and q axis flux \\
\hline$J_{m}$ & Rotor inertia \\
\hline $\mathrm{P}$ & Pole pairs \\
\hline & \\
\hline & \\
\hline
\end{tabular}

REFERENCES

[1] M.Rochdi, M.P.Pushparaj, O.B.Belkacem "Intelligent Mechatronic System: Modeling, Control, Diagnois," Springer-Verlag, pp.3-50, 2013.

[2] N. Zanzouri , K. Mabrouki, "Robust Diagnosis based on BG Modeling Online Implementatiion in the rear Suspension Motorcycle," 3rd Conference on Control and Fault-Tolerant Systems (SysTol), Barcelona, Spain, Sept. 79, pp.239-244, 2016.

[3] J.Nafaa, EL.Lilia, T.Fernando "Modelling and simulation of a BLDC motor speed control system,'Int.J.Electric and Hybrid Vehicles, Vol.8, No.2, pp.178-194, 2016.

[4] S. Dridi, I. Ben Salem, L. El Amraoui, “ Modélisation systémique d'un système de propulsion d'un Moteur-Roue du Véhicule Electrique avec les Bond Graphs", International Conference on Green Energy \& Environmental Engineering (GEEE-2018) Vol.39 pp.12-18, 2018.

[5] S. Dridi, I. Ben Salem, L. El Amraoui, "Dynamic modeling of nonlinear longitudinal automotive system using graphically based techniques", 7th International Conference on Sciences of Electronics, Technologies of Information and Telecommunications (SETIT), pp.349-354, 2016.

[6] S. Dridi, I. Ben Salem, L. El Amraoui, "Dynamic modeling of an automotive power steering graphic tool: Bond graph ", International Conference on Electrical Sciences and Technologies in Maghreb (CISTEM), pp.1-8, 2014.

[7] H. Taghouti and A. Mami. How to Find Wave-Scattering Parameters from the Causal Bond Graph Model of a High Frequency Filter American Journal of Applied Sciences, Vol.7, Issue5, pp. 702-710, 2010.

[8] H. Taghouti and A. MAMI. Discussion around the Scattering Matrix Realization of a Microwave Filter using the Bond Graph Approach and Scattering Formalism. American Journal of Applied Sciences, Vol. 9, Issue 4, pp. 459-467, 2012.

[9] S. Jmal, H. Taghouti and A. Mami. A new modeling and simulation methodology of a patch antenna by bond graph approach. International Conference on Electrical Engineering and Software Applications, pp.16, 2013.

[10] S. Dridi, I. Ben Salem, L. El Amraoui, "Bond Graph modeling of automotive suspension system using a linear actuator ", International Journal of Scientific \& Engineering Research (IJSER), Vol.8, Issue 1, pp. 1837-1844, June-2017, ISSN 2229-5518.

[11] D. Mzoughi, H.Allagui, A. Mami, “A comparative study between a 20sim and a Simulink single PEM cell model, " 15 th international conference on Sciences and Techniques of Automatic control \& computer engineering - STA'2014, Hammamet, Tunisia, December 2123, pp.787-793, 2014.

[12] k. Jaber, B.Ben Salek, A. Fakhfakh, R.Neji, "Modeling and Simulation of Electrical Vehivle in VHDL-AMS," pp.908-911, 2009. (IEEE Conference publication).

[13] K. Jaber, A. Fakhfakh, and R. Neji, "Comparison of SPWM and SVPWM Control of Electrical Vehicle in VHDL-AMS," 6th International Conference on Sciences of Electronics, Technologies of Information and Telecommunications (SETIT), pp.171-176, March 2013.

[14] Logiciel 20sim Controllab Products, 20-sim version 4.1, http://www.20sim.com.

[15] S. Dridi, I. Ben Salem, L. El Amraoui, “ Modélisation systémique basée sur l'outil Bond Graph d'un système de traction de type Moteur-Roue ," International Journal of Scientific Research \& Engineering Technology (IJSET), Đol.6 pp.39-46), Vol.6 pp.39-46, Copyright IPCO2018ĐSSN 2356-5608, 2018. 